\title{
ELECTROPLATING PROCESS FOR COPPER COATING OF CORRUGATED METAL GASKETS TO INCREASE PERFORMANCE
}

\author{
D. Nurhadiyanto* \\ Mechanical Engineering Education, Universitas Negeri Yogyakarta, Indonesia \\ S. Haruyama \\ Graduate School of Innovation and Technology Management, \\ Yamaguchi University, Ube, Japan \\ Mujiyono \\ Mechanical Engineering Education, Universitas Negeri Yogyakarta, Indonesia \\ W. Abbas \\ Mechanical Engineering Education, Universitas Negeri Yogyakarta, Indonesia
}

\begin{abstract}
Corrugated metal gaskets made of SUS304 usually have extremely hard layers that contact the flange. Therefore, they must be designed with an outer covering of a softer material. For three-layer gaskets, however, this process is challenging. This paper proposes the coating of corrugated metal gaskets with copper to obtain softer layers and reports on the degree of adhesion of SUS304 with copper. The coating process employs the electroplating method. The results show that there are no cracks or breaches between the metal and copper, and these materials completely enclose SUS304. Cracks also do not occur after the gaskets have been used to seal flange leakage. Furthermore, the copper layers are likely to be durable, showing no changes between before and after use on the flange. The performance of coated corrugated metal gasket was better than standard corrugated metal gaskets.
\end{abstract}

Keywords: coating, copper, electroplating, corrugated metal gaskets.

Cite this Article: D. Nurhadiyanto, S. Haruyama, Mujiyono, W. Abbas, Electroplating Process for Copper Coating of Corrugated Metal Gaskets to Increase Performance. International Journal of Mechanical Engineering and Technology 11(1), 2020, pp. 73-83.

https://iaeme.com/Home/issue/IJMET?Volume=11\&Issue $=1$ 


\section{INTRODUCTION}

Currently developed corrugated metal gaskets still contend with problems related to flange surface roughness and hardness of the gasket material, which can impair their function as a leak-free sealant for flange unevenness. It requires the softer material on the surface of corrugated metal gaskets. Softer material will fill in the surface roughness of flanges and prevent the leakage. What kind of the good process to coating corrugated metal gasket?

Haruyama et al. [1] previously investigated the effect of flange surface roughness on leakage; however, the study has its weakness, namely the use of a high pressing force to prevent gas from leaking. A high flange roughness still cannot withstand helium gas leakage. Haruyama et al. [2] and Karohika et al. [3] later modified the standard gasket by softening its outer layers. The forming process was designed to produce three layers, namely copperSUS304-copper, where the outer layers are thinner than that of SUS304. However, as a result of the difficult forming process, the copper layer cannot perfectly cover the metal. Nurhadiyanto et al. [4] performed a finite element method (FEM) analysis on a copper-coated SUS304 gasket. Because copper is softer than SUS304, it can fill the roughness of the flange surface. The analysis showed that copper coating increases the contact width and decreases the contact stress. The reduction in contact stress enables grazing of the gasket to form a circular line on the gasket, which closes the leak. To prove these results, an experiment was performed by coating nickel and copper onto a corrugated metal gasket. Corrugated metal gaskets were then tested for leakage using a water pressure test. In addition to this analysis, Margen et al. [5] conducted an AISI304 stainless steel coating experiment with nickel-coated copper by considering a time variable and a fixed electric current parameter. Copper coating effectively occurred on the stainless steel material, with the best results obtained at a current of $1.5 \mathrm{~A}$ and time of $180 \mathrm{~s}$. The thickness of the copper attached to the stainless steel was suggested as $26.50 \mu \mathrm{m}$. Dinu et al. [6] also carried out a stainless-steel coating experiment with a single layer of $\mathrm{Cr}-\mathrm{N}$ and $\mathrm{Cr}(\mathrm{N}, \mathrm{O})$ and a bilayer of $\mathrm{Cr}-\mathrm{N} / \mathrm{Cr}(\mathrm{N}, \mathrm{O})$ and $\mathrm{Cr}(\mathrm{N}, \mathrm{O}) / \mathrm{Cr}-\mathrm{N}$ on steel 304 by means of the reactive cathodic arc method. This experiment resulted in a compact structure, low-porosity coating, and more refined surface.

Based on the above results, in this study, the coating of a corrugated metal gasket with copper was carried out through the electroplating process. The gasket material, SUS304, was first formed into a gasket, to which the copper coating process was then applied. The copper layers are expected to permeate the flange roughness and thereby plug the leakage. The current study performed copper coating on corrugated metal gaskets comprised mainly of SUS304, determined the degree of adhesion between SUS304 and the copper layer, and ascertained whether there are cracks in the copper layer both before or after use.

\section{MATERIALS AND METHOD}

The basic material for the researched gasket is SUS304, which has a nominal stress of 398.8 $\mathrm{MPa}$, tangent modulus of $1900.53 \mathrm{MPa}$, and modulus of elasticity of $210 \mathrm{GPa}$. The coating material is copper, which has a nominal voltage of $195 \mathrm{MPa}$, tangent modulus of $1150 \mathrm{MPa}$, and modulus of elasticity of $115 \mathrm{GPa}$ [7] [8]. Of the two materials, copper has softer characteristics. The two materials are temperature and chemical resistant.

The gasket was in the form of a disc with two corrugated layers on the upper and lower sides. To form a waving pattern, dies were used in a cold-forming process. The gasket diameter was primed to comply with the JISB2404 standard [9], and the wave dimensions were obtained from the optimum design based on FEM analysis using the Taguchi method. The flange material was the same as that of the gasket, namely SUS304 in the form of a general-purpose flange based on JISB2220 [10]. The corrugated metal gasket produced by the forming process at room temperature and pressure [1] can be seen in Fig. 1. 


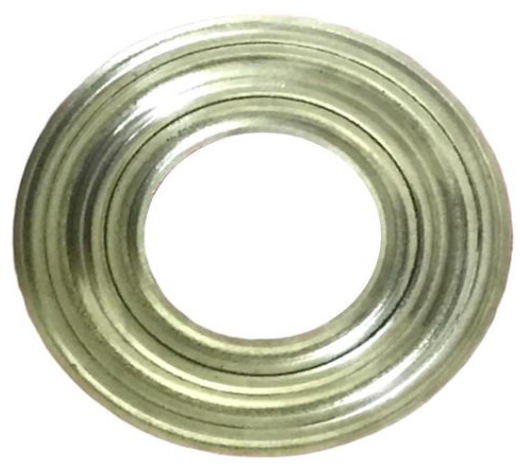

Figure 1. Corrugated metal gasket

Electroplating is a process of coating a metal with another metal with the aid of an electric current. The quality of the coating metal can be retained by the coated material. The main purpose of this process is to improve the surface quality of an object, for example by making the object more resistant to corrosion, aesthetically pleasing, resistant to abrasion, harder, softer, etc. An illustration of the electroplating process can be seen in Fig. 2. Electroplating is used in various industries, including automotive, jewelry, construction and building, electrical equipment, electronic equipment and connectors, fashion, sanitation, and packaging [11].

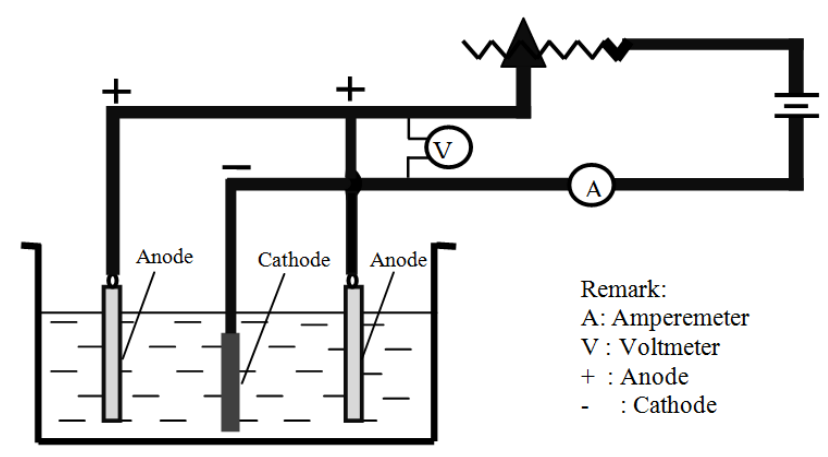

Figure 2. Circuit for the electroplating process

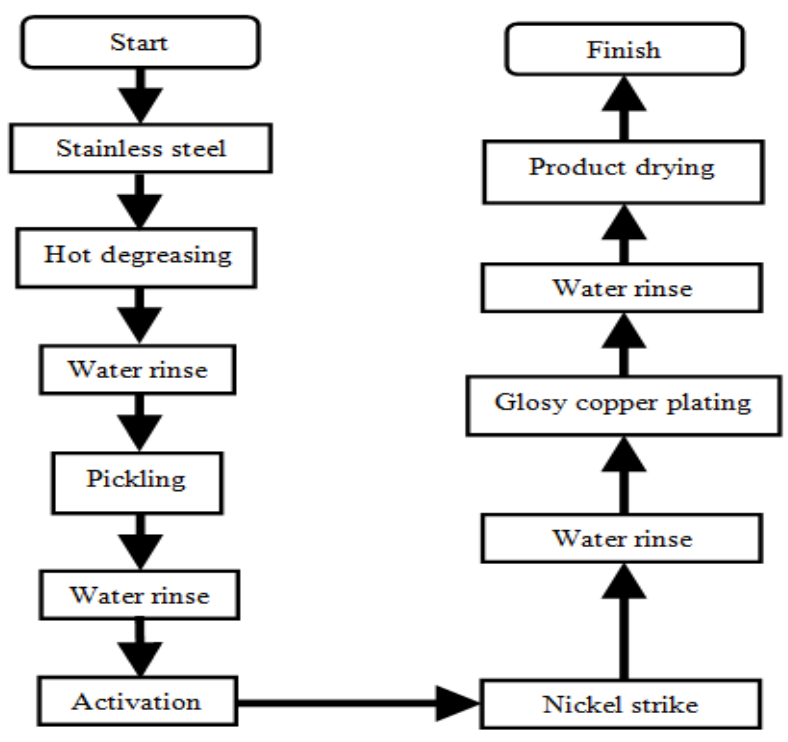

Figure 3. Diagram of stainless-steel electroplating process 
In principle, the coating process is an electrochemical deposition process. The object to be coated must be placed in the electrolyte as a cathode; the deposited metal is usually used as an anode. An overall diagram of the electroplating process is presented in Fig. 3.

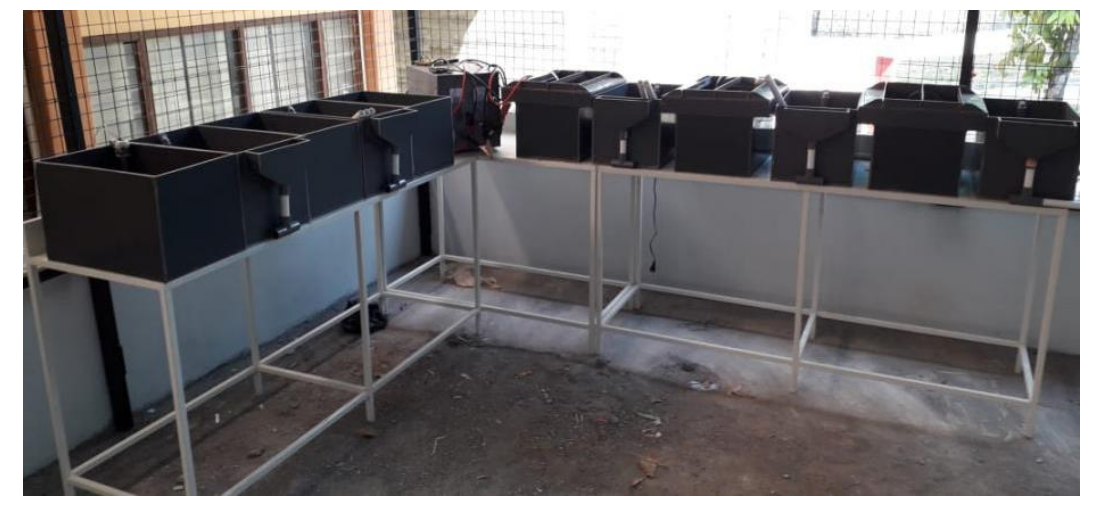

Figure 4: Electroplating equipment

The electroplating stages in Fig. 3 were carried out experimentally using the equipment shown in Fig. 4. The hot degreasing stage cleans away grease with an alkaline solution to obtain a completely clean surface free of water break. Washing of grease can be done by dipping, shaking, and rubbing the workpiece for 2-3 min. Fig. 5 shows the hot degreasing process. Then, a water rinse process to clean the soap lasts for 1-2 min, as shown in Fig. 6.

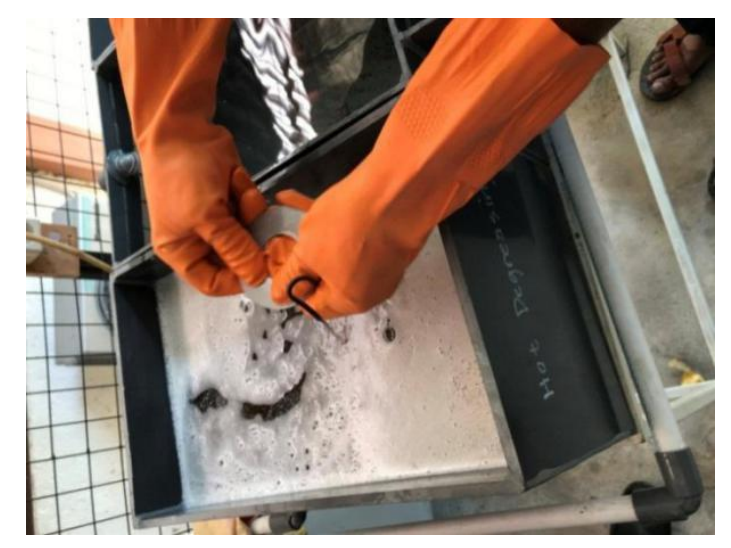

Figure 5. Hot degreasing

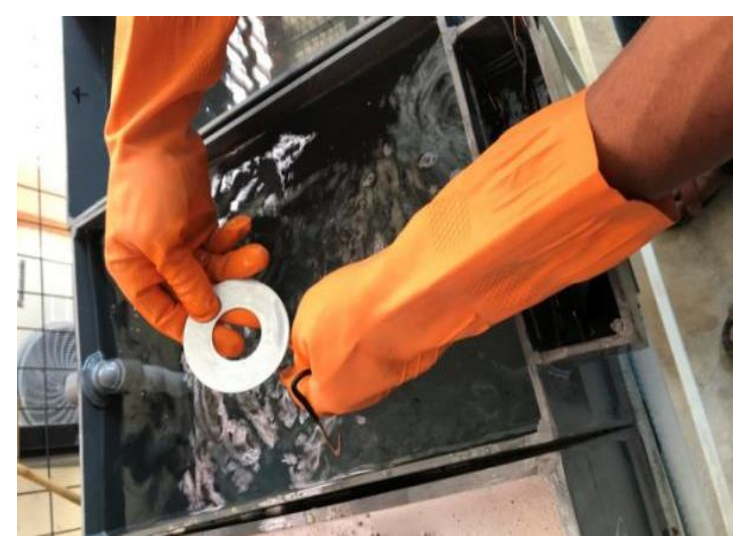

Figure 6. Water rinse 


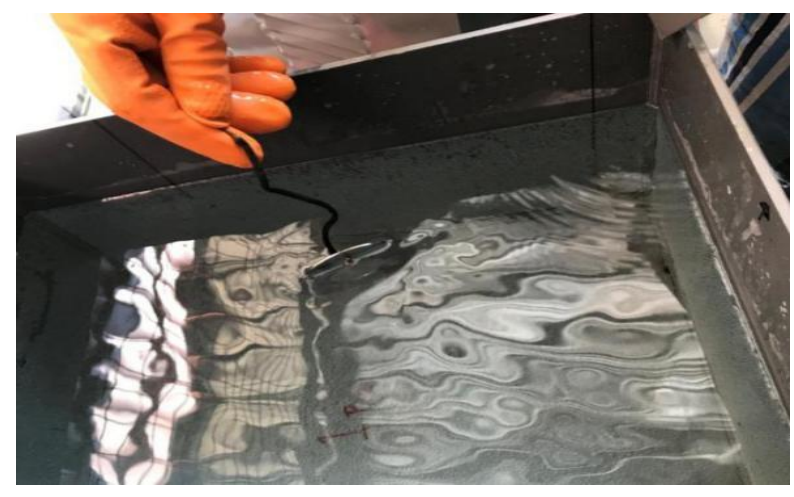

Figure 7. Pickling

The pickling solution comprises water as a solvent and hydrochloric acid $(\mathrm{HCl})$ as a solute up to a concentration of $20 \%$ as seen in Fig. 7. The pickling process removes rust by immersing the gasket in the solution for $15 \mathrm{~min}$. Another water rinse is performed before the next process. Then, the activation process is performed using $30 \% \mathrm{H}_{2} \mathrm{SO}_{4}$ with a $\mathrm{pH}$ of 4.5 and dipping the stainless steel for approximately 1 min or until gas is released from the object. This is to activate and expose the ions to be coated with copper. Fig. 8 shows the activation process.

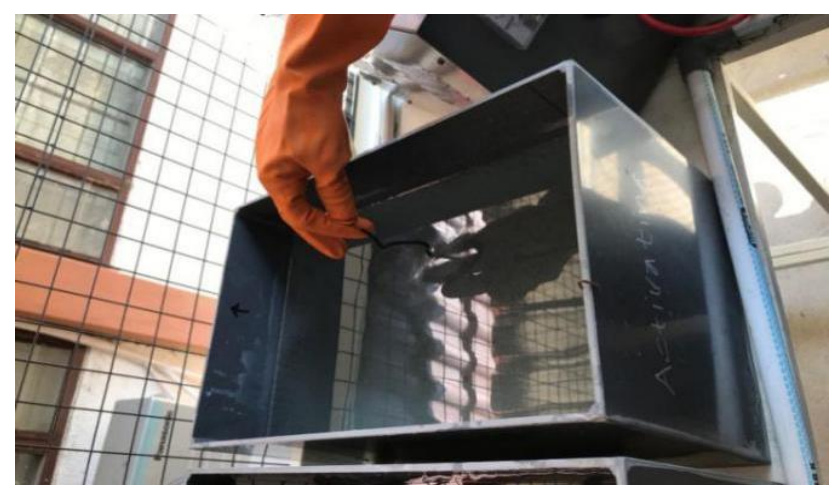

Figure 8. Activation

The subsequent phase is nickel strike plating as depicted in Figure 9. This step is only performed if the object to be coated is stainless steel because it is not a conductor. The nickel coating solution is composed of nickel chloride $\left(\mathrm{NiCl}_{2} \cdot 6 \mathrm{H}_{2} \mathrm{O}\right)$ at $240-300 \mathrm{~g} / \mathrm{L}$ and pure hydrochloric acid at $86 \mathrm{~g} / \mathrm{L}$. The nickel strike process is carried out by dipping the workpiece in the solution with the anode for $2 \mathrm{~min}$ and with the cathode for $3 \mathrm{~min}$. The next process is initiated when water appears on the plate.

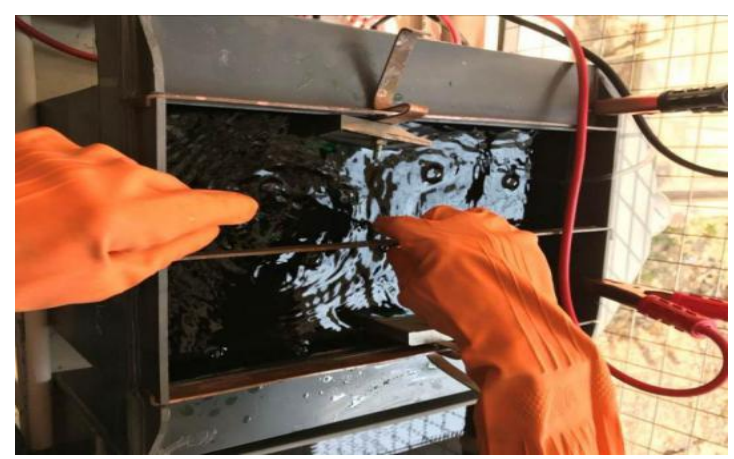

Figure 9. Nickel strike plating 


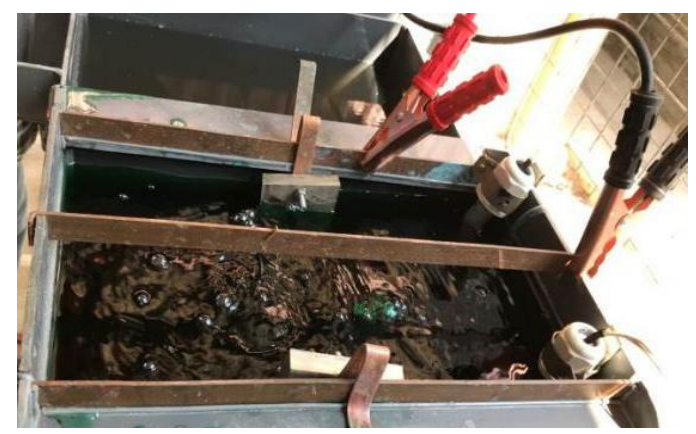

Figure 10. Glossy copper plating

The nickel strike plating process requires unalloyed nickel as the anode material. The glossy copper plating process requires uncontaminated copper material as the anode, while the cathode is the material to be coated - the gasket. Fig. 11 show the pure copper materials.

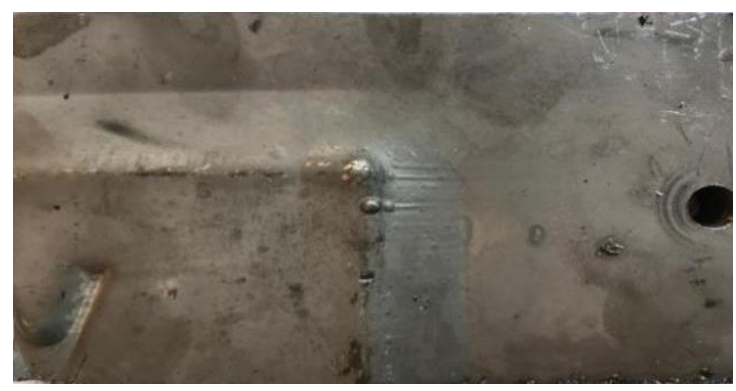

Figure 11. Copper material

After the gasket is formed into a corrugated metal gasket, the next coating process employs the copper material. The thickness of the copper layer varies between $20 \mu \mathrm{m}$ and 30 $\mu \mathrm{m}$. Fig. 12 shows a gasket that has been coated with copper.

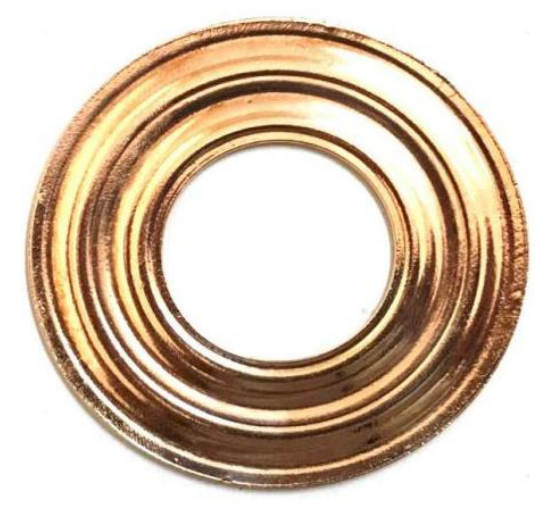

Figure 12. Gasket coated with copper

The corrugated metal gaskets coated with copper are cut into appropriate specimens. These samples are taken from copper coatings. Before microstructure test measurements, sanding is carried out at up to 1500 finesse. To facilitate sanding, a holder was created using resin as shown in Fig. 13. 


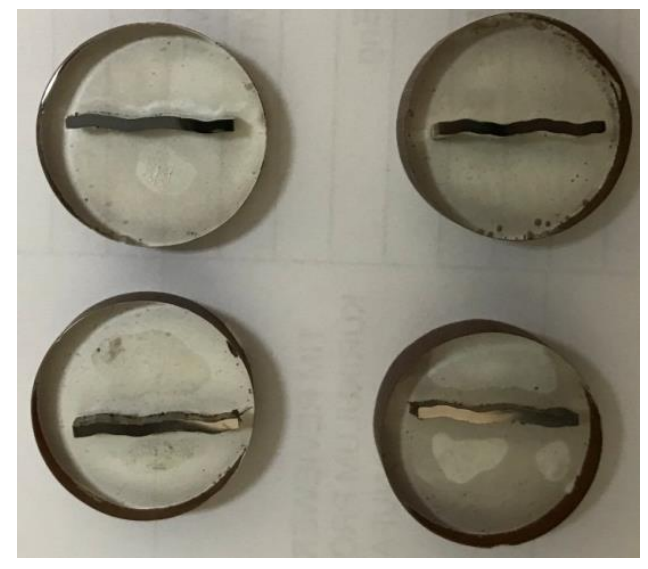

Figure 13. Microstructure test specimens

The performa of gasket standard and coated gasket checked by leakage test. The water pressure test used to mesured leakage of gasket before and after coating by copper. The pressure of water was $7.5 \mathrm{MPa}, 10 \mathrm{MPa}$ and $12 \mathrm{MPa}$. The clamping load of bolt was $40 \mathrm{kN}$, $60 \mathrm{kN}, 80 \mathrm{kN}$, and $100 \mathrm{kN}$.

\section{RESULTS AND DISCUSSIONS}

The deposition speed during the electroplating process is determined according to Faraday's law, which requires that the weight of the deposited metal be linearly proportional to the current and time. This statement is summarized as Eq. (1).

$$
\mathrm{W}=\frac{A_{y} \mathrm{I} \text {. t }}{Z_{A} 96500,}
$$

$$
\begin{array}{cl}
\text { where } & \quad A_{\mathrm{r}}: \text { atomic weight } \\
Z_{\mathrm{A}} & : \text { valence electron } \\
I & : \text { current } \\
t & : \text { time. }
\end{array}
$$

Layer density $(\rho)$ is given by Eq. (2), and layer thickness can be calculated using Eq. (3).

$$
\begin{aligned}
& \mathrm{p}=\frac{\text { Layer weight }}{\text { Layer volume }} \\
& \text { layer thickness }=\frac{\text { Layer weight }}{\mathrm{p} \cdot \text { Layer area }}
\end{aligned}
$$

The coated area is the area of both sides plus the outer and inner circumferences. The dimensions of the gasket include the outer diameter $(D)$ of $74.6 \mathrm{~mm}$, inner diameter $(d)$ of $35.1 \mathrm{~mm}$, and gasket thickness $(t)$ of $1.6 \mathrm{~mm}$. Using these dimensions, the total area covered was calculated as $7354.1828 \mathrm{~mm}^{2}$. The specific gravity of the copper material is $8.96 \mathrm{~g} / \mathrm{cm}^{3}$ or $0.00896 \mathrm{~g} / \mathrm{mm}^{3}$.

Table 1 and Fig 14 show the data corresponding to copper electroplating on. the corrugated metal gasket. The copper electroplating process uses a current of $3 \mathrm{~A}$. Based on Table 2, the average coating weight after 40 min was $3.12 \mathrm{~g}$. Then, we can calculate the coating thickness using Eq.(4) and Eq.(5). 
D. Nurhadiyanto, S. Haruyama, Mujiyono, W. Abbas

$$
\begin{aligned}
& \rho=\frac{\text { added mass }}{\text { volume }}=\frac{\text { added mass }}{\text { area } \times \text { coating thickness }} \\
& \text { Coating thickness }=\frac{\text { added mass }}{\text { area } \times \rho}=\frac{3.12}{7354.1828 \times 0.00896}=0.0224 \mathrm{~mm}
\end{aligned}
$$

Table 1: Copper coating weight data

\begin{tabular}{ccccc}
\hline \multirow{2}{*}{ No } & $\begin{array}{l}\text { Initial } \\
\text { Weight }\end{array}$ & \multicolumn{3}{c}{ Shiny Copper Weight (gram) } \\
\cline { 3 - 5 } & (gram) & 20 minutes & 10 minutes & 10 minutes \\
\hline 1 & 39.75 & 40.75 & 41.77 & 42.85 \\
2 & 39.91 & 40.97 & 41.64 & 42.68 \\
3 & 39.87 & 41.10 & 41.86 & 42.56 \\
4 & 39.97 & 41.66 & 42.87 & 43.93 \\
5 & 40.06 & 41.09 & 42.10 & 43.09 \\
Avrg & 39.912 & 41.1175 & 42.048 & 43.022 \\
\hline
\end{tabular}

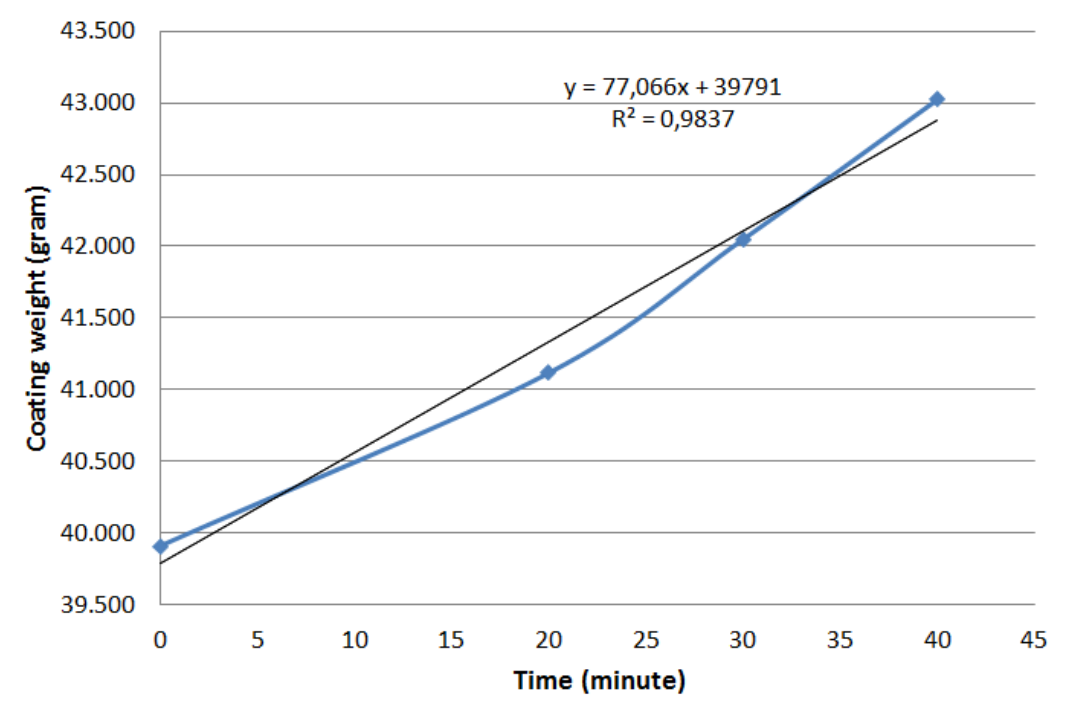

Figure 14. Added weight by copper coating based on time

Based on the above calculation, $36 \mathrm{~min}$ are required to obtain a layer thickness of $20 \mu \mathrm{m}$, while a thickness of $30 \mu \mathrm{m}$ can be obtained in $53.63 \mathrm{~min}$. Thus, we can determine the electroplating time required to obtain copper layers with a thickness of $20 \mu \mathrm{m}$ and $30 \mu \mathrm{m}$. In this case, a certain thickness can be obtained by increasing or decreasing the duration of the electroplating process.

The next stage focused on determining the degree of adhesion between the copper coating and gasket. This adhesiveness was analyzed using a microstructure test. The adhesiveness of the copper coating is illustrated in Fig. 15 and 16. 


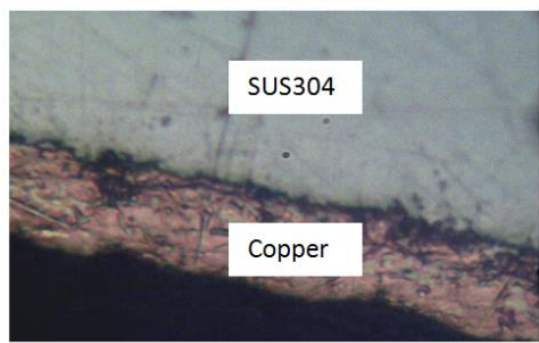

(a) Lower part

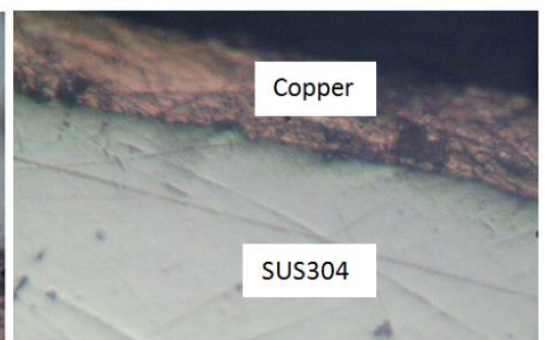

(b) Upper part

Figure 15. Adhesiveness of copper coating to gasket after use

Fig. 15 shows the microstructure test results of the corrugated metal gasket coated with copper that had already been used on flanges to prevent leakage. The photos show the upper and lower parts of the gasket. The brown color appearing on the edge is a layer of copper. On the top and bottom sides between SUS304 and copper, a dividing line between the two layers is present. This means that there is no diffusion between SUS304 and copper and that copper is only attached to SUS304.

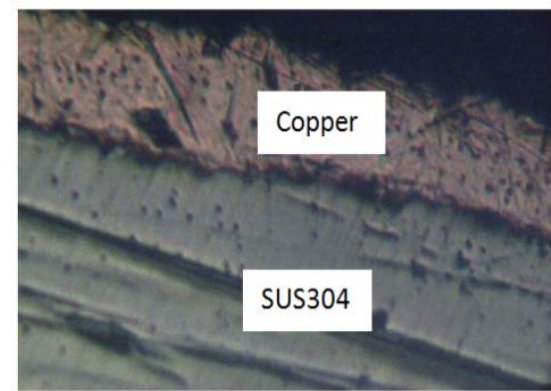

(a) Upper part

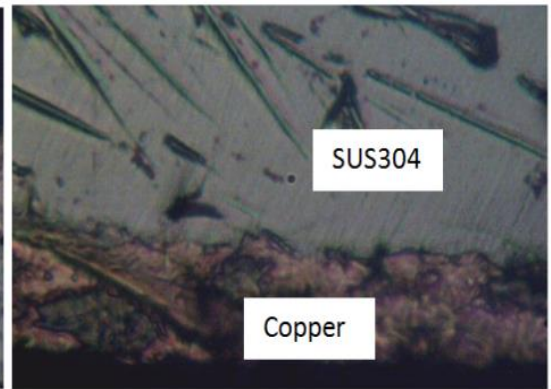

(b) Lower part

Figure 16. Adhesiveness of copper coating to gasket before use

Figure 16 shows the microstructure test results of the corrugated metal gasket coated with copper that had not yet been used on a flange to prevent leakage. Similar to the previous images, appearing on the edges is a brown color corresponding to the copper layer. On the top and bottom parts, a dividing line between the two layers appears between SUS304 and copper, again indicating that there is no diffusion between SUS304 and copper and that copper is simply attached to SUS304.

Thus, the microstructure test results show that there is no diffusion between copper and SUS304. There was also no difference between the adhesiveness of copper to SUS304 before and after the gasket was used to prevent leakage on a flange. The copper layer covers a large area and does not break; this remains the same before and after the gasket is used.

Fig. 17 shows the measurement result of leakage using water pressure test. Furthermore, it is necessary to check the performance of the gasket after copper coating. The initial experiment using the corrugated metal gasket coated with copper yielded a good performance, where the coated corrugated metal gasket performed better than the standard corrugated metal gasket. Copper material filled in the surface rougness of flange, so the water will stoped by copper material. The thickness of coated corrugated metal gasket $30 \mu \mathrm{m}$ is better than $20 \mu \mathrm{m}$. Copper material of coated $30 \mu \mathrm{m}$ filled more than $20 \mu \mathrm{m}$ in the surface rougness of flange. This was clarified in an FEM analysis of a corrugated metal gasket coated by copper [4]. 
D. Nurhadiyanto, S. Haruyama, Mujiyono, W. Abbas

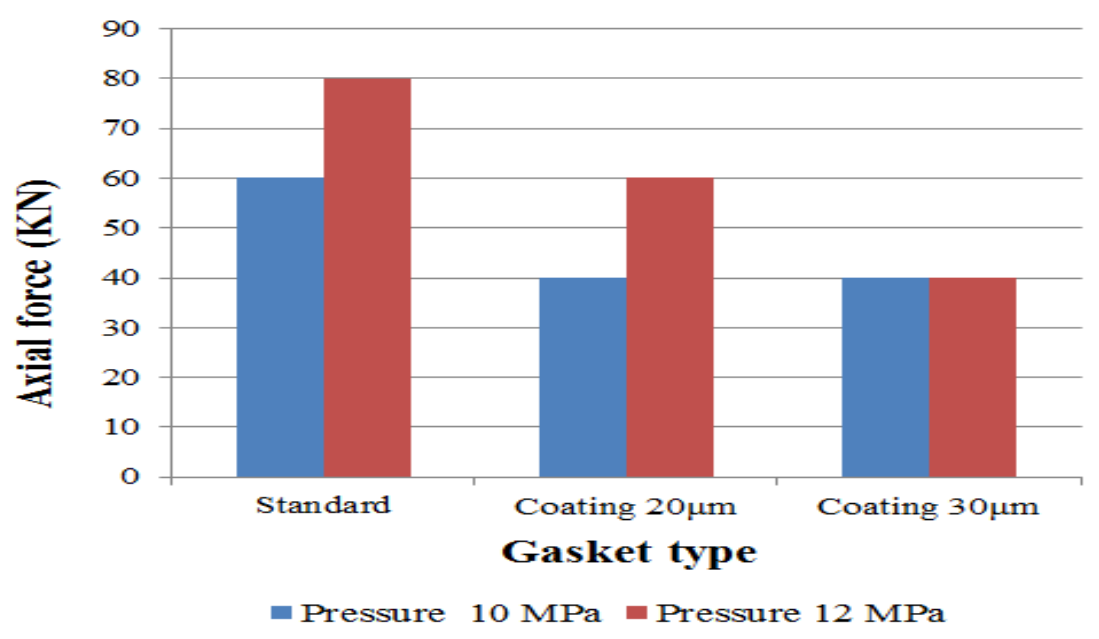

Figure 17. Experiment result of leakage meusurement

\section{CONCLUSIONS}

Based on the coating experiment and microstructure test results in this study, the following conclusions are presented. The proposed appropriate coating process is electroplating. For the electroplating process to work, the stainless steel must first be activated, and thus the nickel strike process must first be performed to expose the SUS304 ions. Then, glossy copper can be electroplated as required. There seems to be no diffusion between SUS304 and the copper material, and thus the coating material only sticks to the base material. The attachment of the coating material is likely to be quite good, and there are no cracks on the gasket either before or after it is used. Another proof of the lack of cracks is the absence of leakage during use.

\section{ACKNOWLEDGEMENTS}

This project was supported by the Faculty of Engineering, Universitas Negeri Yogyakarta by the scheme of "Research Group" in 2019. We would like to thank Editage (www.editage.com) for English language editing.

\section{REFERENCES}

[1] S. Haruyama, D. Nurhadiyanto, M. A. Choiron, K. Kaminishi. "Influence of surface roughness on leakage of new metal gasket." International Journal of Pressure Vessels and Piping 111-112, pp 146 - 154, 2013.

[2] S. Haruyama, I. M. G. Karohika, A. Sato, D. Nurhadiyanto, K. Kaminishi. "Development of 25A-size three-layer metal gasket by using fem simulation." International Journal of Mechanical, Aerospace, Industrial, Mechatronics and Manufacturing Engineering 10(3), pp $527-533,2016$.

[3] I. M. G. Karohika, S. Haruyama, K. Kaminishi, O. Oktavianty, D. Nurhadiyanto. "Analysis of contact width and contact stress of three-layer corrugated metal gasket." International Journal of Mechanical, Aerospace, Industrial, Mechatronics and Manufacturing Engineering 11(4), pp 870 - 879, 2017.

[4] D. Nurhadiyanto, Mujiyono, Sutopo, F. A. Ristadi. "Simulation analysis of 25A-size corrugated metal gasket coated copper to increase its performance." IOP Conference Series: Materials Science and Engineering 307: 012005, 2018.

[5] S. Y. Margen, S. Sulistyo, S. Nugroho, Y. S. A. Nugroho. "Enhancement surface coating stainless steel and copper using ultrasonic batch." MATEC Web of Conferences. 159:02051, 2018. 
Electroplating Process for Copper Coating of Corrugated Metal Gaskets to Increase Performance

[6] M. Dinu, E. S. M. Mouele, A. C. Parau, A. Vladescu, L. F. Petrik, M. Braic. "Enhancement of the corrosion resistance of 304 stainless steel by $\mathrm{Cr}-\mathrm{N}$ and $\mathrm{Cr}(\mathrm{N}, \mathrm{O})$ coatings." Coatings 8(4) 132, 2018.

[7] Materials data book, Cambridge University Engineering Department, 2003 Edition.

[8] Cambridge Engineering Selector software (CES 4.1), Granta Design Limited, Rustat, 2003.

[9] JISB2404, Dimensions of gaskets for use with the pipe flanges, Japanese Standards Associations, 2006.

[10] JIS B2220, Steel pipe flanges, Japanese Standards Association, 2004.

[11] P. N. Belkin, A. Yerokin, S. A. Kusmanov. "Plasma electrolytic saturation of steel with nitrogen and carbon." Surface and Coatings Technology 307(C), pp 1194 -1218, 2016. 